\title{
Qual é a área máxima da casa? Um problema à luz da resolução de problemas mediada pela tecnologia
}

\section{What is the maximum area of a house? A problem from the perspective of technology-oriented problem solving}

\author{
Dienifer Tainara Cardoso Lickefett \\ Ivanete Zuchi Siple \\ Elisandra Bar de Figueiredo
} \begin{abstract}
de funções. Adotando uma abordagem qualitativa e interpretativa, foram recolhidos os dados das resoluções de uma atividade realizada pelos alunos de uma turma do Ensino Médio e outra do Ensino Superior. Nos resultados, apontamos as potencialidades sobre 0 uso da tecnologia que favoreceu a resolução do problema devido à abordagem interativa e à possibilidade de transitar entre diferentes representações, bem como alguns desafios presentes em determinadas etapas da metodologia adotada.
\end{abstract}

Resumo: Neste artigo apresentamos resultados parciais de uma pesquisa, em nível de mestrado profissional, sobre o contributo do uso da metodologia de ensino-aprendizagem-avaliação através da resolução de problemas mediada pelo GeoGebra, em conexão com os diferentes registros de representações, no ensino e na aprendizagem, de máximos e mínimos de funções. $O$ produto educacional, oriundo dessa pesquisa foi um Caderno Didático na plataforma do GeoGebra, composto por diversos aplicativos que buscam auxiliar na resolução de problemas de otimização

Palavras-chave: Resolução de Problemas. GeoGebra. Representações. Máximos e Mínimos. Funções.

Abstract: This paper presents the partial results of a Master's-degreelevel research project on the contribution of employing the teachinglearning-assessment methodology through problem solving using GeoGebra, in connection with the different registers of representations, in teaching and learning the maxima and minima of functions. The educational product derived from this research was a didactic booklet, developed using the online GeoGebraBook tool, composed of several applications that seek to assist in the resolution of function optimization problems. Adopting a qualitative and interpretative approach, data were collected on the solutions of an activity tested in two pilot classes, one in high school and another in an undergraduate program. In the results,
Dienifer Tainara Cardoso Lickefett Mestre em Ensino de Ciências, Matemática $e$ Tecnologias. Professora da EMEF Pe. Mathias Maria Stein, em Guaramirim. Santa Catarina, Brasil.

(iD) orcid.org/0000-0002-5394-4844 $\bowtie$ cardoso.dienifer@gmail.com

Ivanete Zuchi Siple Doutora em Engenharia de Produção. Professora do Programa de Pós-Graduação em Ensino de Ciências, Matemática e Tecnologias da Universidade do Estado de Santa Catarina (UDESC). Santa Catarina, Brasil.

(iD) orcid.org/0000-0002-8640-1336 $\triangle$ ivanete.siple@udesc.br

Elisandra Bar de Figueiredo Doutora em Matemática. Professora do Mestrado Profissional em Matemática em Rede Nacional da Universidade do Estado de Santa Catarina (UDESC). Santa Catarina, Brasil.

(iD) orcid.org/0000-0003-2101-4009 $\triangle$ elisandra.figueiredo@udesc.br

Recebido em 28/04/2020 Aceito em 09/06/2020 Publicado em 10/07/2020 we will point out the potential regarding the use of technology that favored the resolution of the problem due to the interactive approach and the possibility of transition between different representations, as well as some challenges in certain stages of the adopted methodology.

Keywords: Problem solving. GeoGebra. Representations. Maxima and Minima. Functions. 


\section{Introdução}

Este artigo é oriundo de uma pesquisa de Mestrado Profissional em Ensino de Matemática que envolveu a temática de ensino e aprendizagem de máximos e mínimos, ou otimização, de funções (CARDOSO, 2018a). Esse conteúdo faz parte do currículo do Ensino Médio e dos cursos de Ensino Superior de várias áreas, tais como Matemática, Engenharias, Economia, Administração, dentre outras. Maximizar lucros, minimizar custos, maximizar áreas ou volume são algumas das diversas aplicabilidades desse conteúdo.

Nos Parâmetros Curriculares Nacionais para o Ensino Médio (PCNEM), defende-se que é fundamental que o aluno saiba "interpretar, fazer uso e elaborar modelos e representações matemáticas para analisar situações; por exemplo, utilizar funções ou gráficos para modelar situações envolvendo cálculos de lucro máximo ou prejuízo mínimo" (BRASIL, 2002, p. 117). No Ensino Superior, máximos e mínimos de funções é visto como uma das aplicações de derivada na disciplina de Cálculo Diferencial e Integral (CDI). O estudo de derivada possibilita ao aluno otimizar diversas funções, além da função quadrática, comumente abordada no Ensino Médio.

O CDI é uma ferramenta muito importante para que o (futuro) professor compreenda a importância dos conceitos de funções e suas aplicações vistas desde a Educação Básica, assim como ampliar a sua visão sobre o desenvolvimento da própria Matemática, conforme aponta 0 Boletim da Sociedade Brasileira de Matemática (SBEM) sobre reflexões acerca da formação do professor de Matemática:

O Cálculo Diferencial e Integral é a porta para a Matemática Superior de um licenciando como uma extensão necessária para compreender as questões delicadas mencionadas e que embasam a atitude do professor diante das dificuldades conceituais que poderá enfrentar em sua profissão (SBEM, 2013, p. 19-20).

Por outro lado, podemos nos questionar por que, em geral, os alunos apresentam tantas dificuldades de aprendizagem na disciplina de Cálculo? Pesquisas buscam compreender a dificuldade apresentada pelos alunos na disciplina de CDI. Segundo os Marin e Penteado (2011, p. 529), uma delas está atrelada à dificuldade do professor em se "familiarizar com novas metodologias", colaborando para que as aulas sejam direcionadas ao formalismo que, no entender de Richit et al. (2012), é quando os alunos apenas memorizam os exercícios, os conceitos e as demonstrações, dificultando a aprendizagem. Nesse sentido, 
educando e envolver uma matemática que não se volte exclusivamente para seus fundamentos lógicos, para uma linguagem formal artificializada, para a extrema precisão exigida pelo rigor científico correspondente ao atual estágio de desenvolvimento da matemática acadêmica. Ao mesmo tempo, deve desenvolver uma matemática que ultrapasse o simples uso mecânico de fórmulas, algoritmos e procedimentos memorizados, sem consistência, sem origem e sem finalidade, pelo menos para os estudantes em formação escolar. (SBEM, 2013, p. 5)

Para Duval (2012a), é fundamental, na atividade matemática, poder mobilizar muitos registros de representação semiótica, tais como gráficos, linguagem simbólica, linguagem natural, no decorrer de uma mesma etapa, optar por um registro no lugar de outro.

Para podermos manipular com sucesso a informação que dispomos para a resolução de uma dada situação matemática, como por exemplo um problema, torna-se necessário que as várias representações estejam corretas e fortemente ligadas de modo a selecionar aquela que for mais eficiente para o próximo passo que queremos dar. $O$ ensino e a aprendizagem deste processo de conexão entre as diferentes representações são difíceis por exigir capacidade de lidar com as diferentes formas de informação que elas veiculam. Os alunos revelam, geralmente, alguma falta de experiência e acabam por utilizar apenas uma das representações, o que pode deverse a um ensino que valorize somente a representação simbólica (VISEU, 2017, p. 269)

No ensino de máximos e mínimos de funções, explorar os diversos registros de representações é de fundamental importância para a compreensão do conteúdo. Por exemplo, quando o professor recorre às representações gráficas como um meio para interpretar conceitos, a visualização pode colaborar positivamente, já que "a visualização não é um fim em si mesma, mas um meio para chegar à compreensão" (ALMEIDA e VISEU, 2002, p. 196).

Assim, é importante nos preocuparmos com a forma e a organização de trabalho em sala de aula, visando instigar a curiosidade do aluno e possibilitar que ele reconheça a Matemática muito além de domínio de técnica, mas como um processo de construção de conhecimento. Segundo Allevato (2005), a metodologia de ensino-aprendizagem-avaliação através da resolução de problemas é um meio que possibilita ao aluno criar conjecturas, explorar conceitos e desenvolver seus conhecimentos. Essa metodologia de ensino tem como objetivo que o aluno seja o construtor de seu próprio conhecimento, baseados no problema que serve como ponto de partida. Assim sendo, os professores são responsáveis por conduzir esse processo (ONUCHIC e ALLEVATO, 2011).

Ademais, essas atitudes de visualizar, conjecturar e explorar estão em sintonia com as potencialidades da tecnologia. Em problemas de máximos e mínimos de funções, a tecnologia permite explorar os parâmetros da função a ser otimizada e sua representação gráfica, facilitando 
a interpretação e construção de estratégias de resolução (SILVA, 2010).

Nesse viés, foi desenvolvido um Caderno Didático com auxílio da ferramenta tecnológica GeoGebraBook (CARDOSO, 2018b). Esse caderno é composto por algumas situações-problema de máximos e mínimos de funções, criadas e outras adaptadas, que podem ser utilizadas por professores e alunos do Ensino Médio e/ou Ensino Superior.

Aqui serão relatados os resultados obtidos na experimentação de uma das sequências didáticas desse Caderno, realizadas em duas turmas - uma de nível Médio e outra, de Ensino Superior. A análise dos resultados foi realizada utilizando pressupostos da pesquisa de abordagem qualitativa e do tipo interpretativa (BOGDAN e BIKLEN, 1994). O relato de outras experimentações pode ser consultado em Cardoso (2018a).

Nesse artigo, apresentaremos como a metodologia de ensino-aprendizagem-avaliação através da resolução de problemas mediada pela tecnologia, com recurso à conexão entre diferentes representações dos conceitos, pode colaborar com o ensino e a aprendizagem de máximos e mínimos de funções.

\section{Diferentes representações no ensino de otimização de funções}

Um dos motivos que leva a Matemática a ser vista como uma ciência difícil de aprender é devido ao seu alto poder de abstração. "Visualizar" em Matemática, nem sempre é algo fácil ou simples. Existem diferentes registros de representações para os conceitos matemáticos, como representação algébrica, gráfica, figural, linguagem natural etc. A transição de diferentes registros, ou ao menos dois dos mencionados anteriormente, quando trabalhada no ensino e na aprendizagem da Matemática, é o que possibilita a compreensão (DUVAL, 2012a).

Dentre os registros de representação, existem as atividades de tratamento e conversão (DUVAL, 2013). O tratamento é a transformação dentro de um mesmo registro, por exemplo, calcular a derivada de uma função no registro algébrico. A conversão é a transformação de um registro a outro, por exemplo, passar do registro algébrico da função derivada para o registro gráfico.

A transformação da linguagem natural para a algébrica, para muitos estudantes se torna um abismo (DUVAL, 2012b). A partir da prática docente e trabalhos como o de Vaz e Gomes (2014), constatamos que na resolução de problemas contextualizados, em que há a necessidade 
de conversão, os alunos se sentem desafiados e é evidente a dificuldade de interpretar e resolver. Ademais, a ordem das conversões também pode alterar o nível de complexidade para 0 aluno. Duval (2009) considera que, "com efeito, quando a conversão se efetua no sentido escritura algébrica de uma equação $\rightarrow$ gráfico, nenhuma dificuldade específica parece surgir. Mas, tudo muda quando é preciso tomar a conversão inversa, mesmo depois de um ensino sobre funções lineares" (p. 78).

A conversão, segundo Duval (2013), na maioria das vezes é necessária principalmente para escolher o registro no qual os tratamentos elementares são mais "fáceis". E, além disso, a conversão é o que conduz aos mecanismos ocultos à compreensão.

Durante a resolução de um problema matemático surge, na maioria das vezes, a necessidade de transitar pelo menos entre a representação da linguagem natural para a algébrica. Por isso, não podemos deixar de falar dos registros de representação quando trabalhamos a metodologia de ensino-aprendizagem-avaliação através da resolução de problemas. A resolução de problemas exige que o aluno utilize seus conhecimentos prévios, diferentes estratégias de resolução e valide os resultados encontrados, o que por sua vez pode necessitar da utilização de diferentes registros de representação, possibilitando que haja a compreensão de determinados conceitos.

\section{Metodologia de ensino-aprendizagem-avaliação através da resolução de problemas}

A Metodologia de ensino-aprendizagem-avaliação da Matemática através da resolução de problemas, foi desenvolvida pelo Grupo de Trabalho e Estudos em Resolução de Problemas (GTERP), formado em 1992, coordenado pela Profa. Dra. Lourdes de la Rosa Onuchic, e tem como característica iniciar o ensino de um tópico a partir de uma situação-problema, a qual gere questionamentos/dúvidas e a necessidade de desenvolver técnicas e conceitos matemáticos como resposta ao problema. Assim, na aprendizagem de Matemática através da resolução de problemas tem-se um caminho que sai do concreto (um problema prático) em direção ao abstrato (simbologias e técnicas matemáticas); o aluno assume um papel mais ativo e o professor conduz esse processo como um mediador.

Nessa concepção, o problema é visto como ponto de partida para a construção de novos conceitos e novos conteúdos; os alunos sendo co-construtores de seu próprio conhecimento e, os professores, os responsáveis por conduzir esse processo. [...]. 
Esse trabalho se apoia na crença de que a razão mais importante para esse tipo de ensino-aprendizagem é a de ajudar os alunos a compreenderem os conceitos, os processos e as técnicas operatórias necessárias dentro das atividades feitas em cada unidade temática e de que o ensino pode ser feito por meio da resolução de problemas. (ONUCHIC e ALLEVATO, 2011, p. 80)

O uso da palavra composta ensino-aprendizagem-avaliação no nome da metodologia tem como objetivo defender que enquanto o professor ensina, o aluno, como ser ativo, aprende, e a avaliação deve ser realizada por ambos (ONUCHIC e ALLEVATO, 2011). Diante disso, essa metodologia é composta por dez etapas, sendo elas: preparação do problema; leitura individual; leitura em conjunto; resolução do problema; observar e incentivar; registros das resoluções na lousa; plenária; busca pelo consenso; formalização do conteúdo; proposição e resolução de novos problemas. As descrições dessas etapas podem ser consultadas em Allevato e Onuchic (2014).

Nessa perspectiva, máximos e mínimos de funções podem ser trabalhados partindo de uma situação-problema, a qual, em grupos, os alunos devem buscar estratégias de resolução, buscando compreender a teoria e prática desse conteúdo. Inclusive, paralelo a isso, o uso da tecnologia pode ser um forte aliado na compreensão do conteúdo e estratégias de resolução.

\section{Software GeoGebra e Caderno Didático}

O GeoGebra é um software gratuito que vem ganhando destaque nas pesquisas acadêmicas em relação ao ensino e à aprendizagem da Matemática (RICHIT et al., 2012; VERHOEF et al., 2015; CARDOSO, 2018a; LEMKE e SIPLE, 2018). Além de poder ser usado online ou instalado no computador, o site do software possui uma comunidade de professores e alunos que colaboram com a divulgação de materiais e aplicativos matemáticos gratuitamente.

Fazendo uso dessa plataforma, foi utilizada a ferramenta GeoGebraBook para desenvolver um Caderno Didático ${ }^{1}$ sobre Máximos e Mínimos de Funções. O Caderno visa disponibilizar diferentes aplicativos e atividades que possam auxiliar no ensino e na aprendizagem desse conteúdo de maneira dinâmica, permitindo que o professor consiga abordar as definições, usando diferentes registros de representações, possibilitando ao aluno explorar os conceitos diante de, pelo menos, dois registros de representações.

Optou-se por essa tecnologia para apresentar o produto educacional devido às

\footnotetext{
1 Link do Caderno Didático desenvolvido: https://www.geogebra.org/m/Qe3PeM2d
} 
potencialidades de experimentação e exploração de múltiplas representações (BORBA e PENTEADO, 2007), bem como pelas possibilidades em manipular, simular e visualizar aspectos conceituais (RICHIT, 2010). Para mais, Onuchic e Allevato (2012, p. 245) afirmam que a tecnologia se torna um grande recurso quando associado à resolução de problemas, pois:

\begin{abstract}
a exploração das possibilidades de representação algébrica, numérica e gráfica que, por exemplo, o computador oferece, a coordenação dessas representações e a compreensão das relações que as vinculam permitem ao aluno conectar conhecimentos que, de outra forma, permaneceriam separados; porém, se conectados, geram compreensões Matemáticas mais amplas e completas [...]. Ao utilizar o computador na Resolução de Problemas que visam à introdução de um novo conceito, o processo subsequente de formalização dos conteúdos matemáticos, conforme tem sido mostrado nas pesquisas atuais, apresenta-se amplamente facilitado devido a esta abordagem empírica e experimental que o computador possibilita. 0 significado de um conceito matemático é interiorizado pelo aluno, tornando o processo de formalização Matemática mais fácil e natural.
\end{abstract}

Com isso, acredita-se que a metodologia de ensino-aprendizagem-avaliação através da resolução de problemas quando mediada pela tecnologia pode colaborar com o ensino e a aprendizagem de máximos e mínimos de funções.

\title{
5 Metodologia de pesquisa
}

Este estudo pretende averiguar como as potencialidades da tecnologia e a metodologia de ensino-aprendizagem-avaliação através da resolução de problemas podem contribuir com 0 ensino e a aprendizagem de máximos e mínimos de funções com alunos do Ensino Médio e Ensino Superior. As experiências ocorreram em sala de aula e no laboratório de informática. Atendendo a conjuntura do objetivo, foi adotada uma abordagem qualitativa e interpretativa (BOGDAN e BIKLEN, 1994) na busca de compreender a resolução de uma situação-problema dos alunos. Nesse viés, os dados foram recolhidos por meio dos registros escritos que os alunos produziram em grupos ou individualmente na resolução da situação-problema (Problema 1 - Área da Casa) proposta com recurso da tecnologia, os registros da professora (autora) e os áudios gravados de alguns grupos. Previamente às experiências, foi solicitada a autorização dos participantes, bem como, a autorização dos pais ou responsáveis pelos alunos menores de idade.

A primeira experimentação realizada foi com a turma do primeiro ano do curso Técnico em Informática Integrado ao Ensino Médio num Instituto Federal. A experimentação nessa turma ocorreu em 7 aulas de 45 minutos, sendo 5 aulas em um primeiro dia no laboratório de informática 
e 2 aulas em outro dia, na sala de aula regular da turma. As primeiras cinco aulas foram em horário adaptado para a experimentação para que fosse possível realizar uma maior quantidade de etapas da metodologia que necessitasse o uso do computador, sendo assim, nesse primeiro dia foram realizadas todas as etapas até a busca pelo consenso (oitava etapa). No segundo dia foi possível concluir a metodologia. No laboratório de informática os alunos puderam utilizar computadores com sistema operacional Linux, Internet, software GeoGebra e demais aplicativos (planilha Calc, processador de textos Writer etc.), além de terem o livro didático da disciplina - Conexões com a Matemática (LEONARDO, 2013). Participaram dessa experimentação um total de 32 alunos.

Em relação à turma do Ensino Superior, a experimentação ocorreu na disciplina de Cálculo Diferencial e Integral I (CDI I), na turma do curso de Licenciatura em Matemática, de uma universidade pública. Porém, também tinham alunos de outros cursos, como Engenharia Civil, Elétrica e Mecânica, matriculados na disciplina, que participaram da experimentação, inclusive alunos que estavam fazendo a disciplina novamente. Para realizar a experimentação foi solicitada a permissão da professora regente da turma, sendo necessários dois dias, com 2 aulas de 50 minutos cada, em um laboratório de informática com sistema operacional Windows, Internet, software GeoGebra e demais aplicativos (planilha Excel, Word etc.). No primeiro dia de experimentação foram realizadas as etapas da metodologia de ensino até o registro das resoluções (sexta etapa) em uma folha $\mathrm{A} 0$. No segundo dia, foi dado continuidade com a plenária, seguida das demais etapas. Nessa experimentação houve a participação de 25 alunos.

Conforme orienta a metodologia de ensino-aprendizagem-avaliação, inicialmente, em cada uma das turmas, o Problema 1 - Área da Casa, que será apresentado na seção seguinte, foi entregue aos alunos e então solicitado que fosse realizada a leitura individual (etapas 1 e 2). Feito isso, os alunos se reuniram em grupos (etapa 3), formando oito grupos na turma do Ensino Médio, que foram chamados de G1, G2, G3, G4, G5, G6, G7 e G8, e sete grupos na turma de Ensino Superior, chamados de E1, E2, E3, E4, E5, E6 e E7. Os grupos eram compostos de três a cinco alunos, exceto o aluno do $\mathrm{E} 6$, que optou por não se juntar em grupo e preferiu fazer as atividades individualmente.

Durante as experimentações, ainda na terceira etapa, enquanto os alunos buscavam compreender o problema em grupo, a professora disponibilizou às turmas um aplicativo do GeoGebra, elaborado por ela, que poderia contribuir na compreensão e resolução da atividade. Enquanto os alunos resolviam o problema (etapa 4), a professora os observava e os incentivava 
nas resoluções (etapa 5). Após discutirem suas estratégias, a professora solicitou que apresentassem a resolução resumidamente, em uma folha A0 (etapa 6) disponibilizada por ela. Feito isso, em plenária, os grupos apresentaram suas resoluções à turma e concluíram, em discussão com a professora, uma possível estratégia de solução para o problema (etapas 7 e 8). Vale ressaltar que na turma do Ensino Superior, nem todos os grupos aceitaram participar da plenária.

Na formalização do conteúdo (etapa 9) em cada turma, a professora buscou trabalhar com auxílio do software GeoGebra e ao menos três representações: gráfica, algébrica e linguagem natural. Na turma do Ensino Superior, por fim, foi disponibilizada uma lista com novos problemas a serem resolvidos e avaliados pela professora regente (etapa 10). Na turma do Ensino Médio os problemas propostos à turma após a experimentação já não fizeram mais parte dessa análise, visto que até naquele momento a autora utilizava como referência as etapas da metodologia de ensino-aprendizagem-avaliação através da resolução de problemas apresentadas no artigo de Allevato e Onuchic (2008), o qual comporta apenas nove etapas.

Vale ainda ressaltar que, antes das experimentações, foi verificado em entrevista ${ }^{2}$ com os professores regentes que os alunos de ambas as turmas já conheciam o GeoGebra, pois era comum sua prática em sala. Desta forma, não houve nenhum contratempo em relação a manipulação do software.

A análise dos dados recolhidos, oriundos das resoluções dos alunos, adotam os modos de representação, tratamento/conversão, estratégias de resolução e uso da tecnologia (DUVAL, 2009; RICHIT, 2010; ONUCHIC e ALLEVATO, 2011).

\section{Apresentação dos resultados}

Nesta seção serão apresentados os resultados das experimentações de cada turma: Ensino Médio e Ensino Superior.

\subsection{Experiência na turma do Ensino Médio}

A situação-problema experimentada refere-se ao cálculo da área máxima de uma casa

\footnotetext{
20 resultado de toda a entrevista pode ser consultado em Cardoso (2018a).
} 
que pode ser obtida considerando que sua construção tenha algumas restrições, conforme apresenta o Quadro 1.

Quadro 1: Atividade aplicada a turma do Ensino Médio - Problema 1 Área da Casa

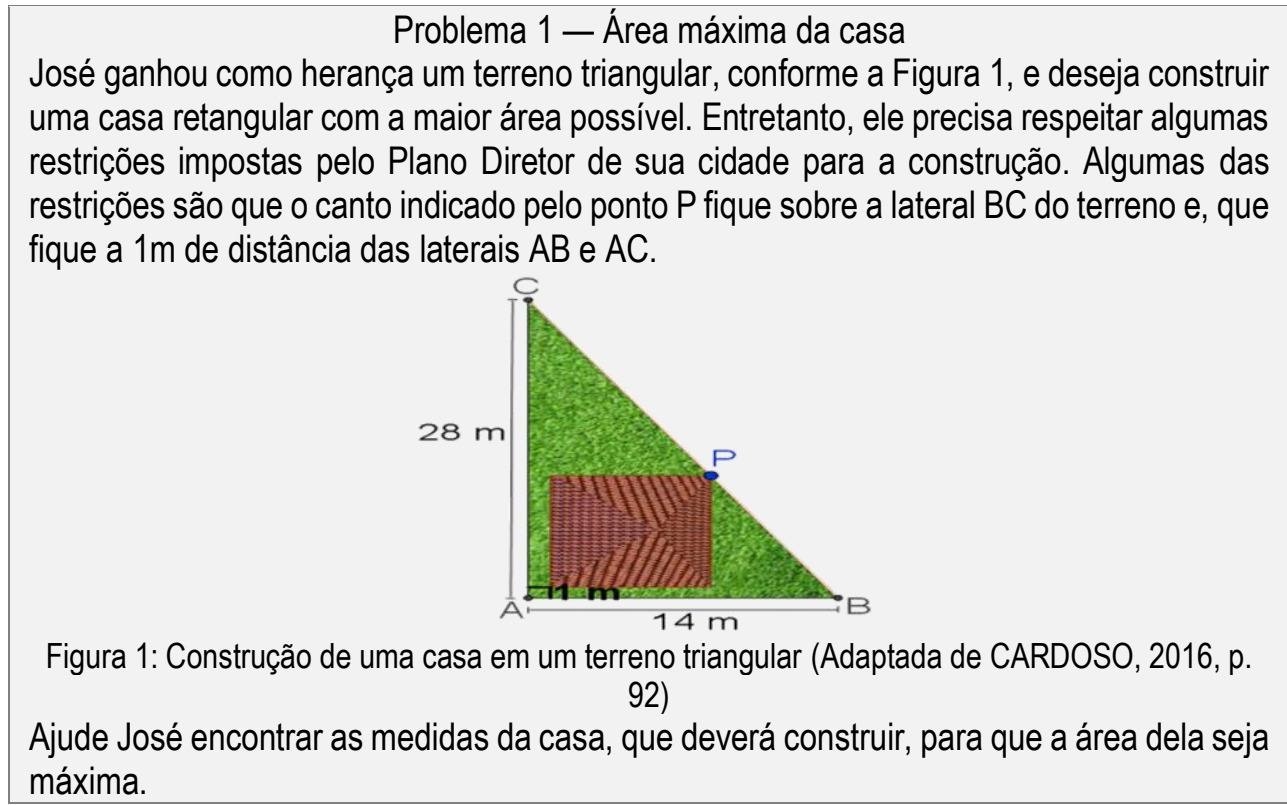

Fonte: Cardoso (2018a, p. 55)

Ao disponibilizar o aplicativo ${ }^{3}$ referente à atividade, infelizmente, os computadores do laboratório não o executaram corretamente devido à incompatibilidade de sistemas operacionais, impossibilitando que os alunos o manuseassem dinamicamente. Porém, muitos alunos haviam levado o notebook particular, o que possibilitou que a maioria dos grupos manuseassem 0 aplicativo normalmente.

Ao iniciar a resolução do problema (quarta etapa), alguns grupos buscaram resolver utilizando conceitos da trigonometria, como cálculo de área de um triângulo, relações trigonométricas e perímetro. Assim calcularam, principalmente, a hipotenusa e área do terreno, como mostra a Figura 1.

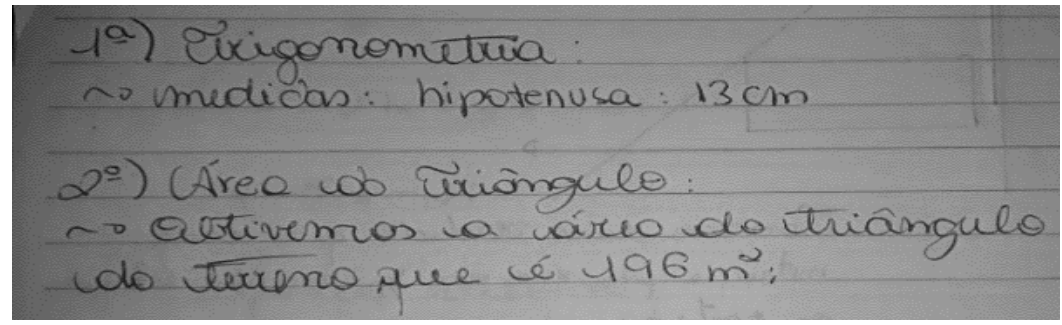

Figura 1: Primeira estratégia do G2 (Dados da Pesquisa)

\footnotetext{
3 Link do aplicativo: https://www.geogebra.org/m/BerFzxRZ
} 
Outra estratégia utilizada por quase todos os grupos na resolução do problema foram conceitos de função polinomial, tanto geometricamente, como algebricamente, baseados no que havia sido visto em sala, como por exemplo, dependência entre as variáveis, estudo dos coeficientes de uma função afim, análise gráfica de função afim e análise gráfica de função quadrática, como será mostrado mais adiante.

Um grupo resolveu o problema utilizando apenas uma estratégia com os conceitos de função. Todos os demais mostraram discutir outras ideias.

Somente um dos grupos não concluiu a função área da casa algebricamente. Os demais grupos observaram a função área da casa utilizando os conceitos de trigonometria e/ou função polinomial, citados anteriormente. A função área encontrada será apresentada a seguir durante 0 relato detalhado sobre as estratégias de alguns grupos.

Por observação da professora e áudios transcritos, constatou-se que os alunos utilizaram a internet em alguns momentos para buscar estratégias de resolução, pesquisando por exemplo: fórmulas de cálculo de área de figuras planas, relações trigonométricas, teorema de Tales, coeficientes das funções afim e quadrática e as fórmulas das coordenadas do vértice da parábola.

O grupo G5 usou como estratégia inicial conceitos de função e trigonometria. Partiu da hipótese que a área máxima da casa podia ser obtida como um ponto de máximo de uma função quadrática. Assim, seus integrantes criaram a conjectura que esse ponto máximo seria obtido quando o ponto $\mathrm{P}$ fosse o ponto médio do segmento BC (Figura 2).

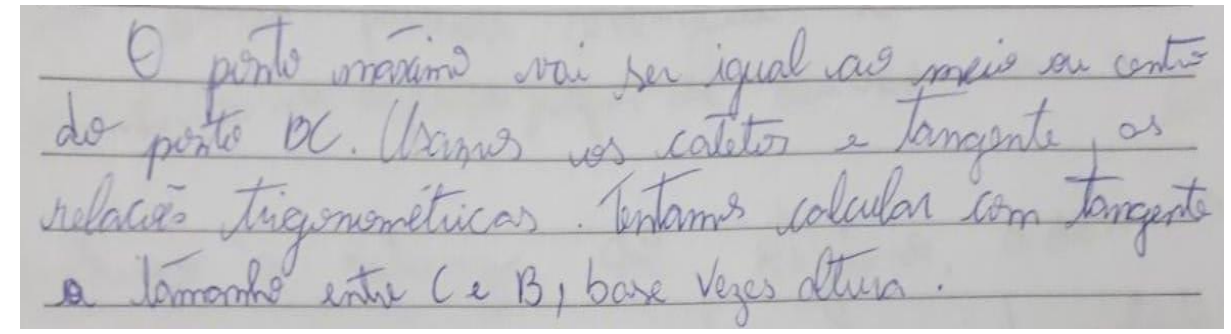

Figura 2: Primeira Estratégia G5 (Dados da Pesquisa)

Nesse momento o grupo realizou uma conversão entre uma representação figural do ponto máximo com o gráfico de uma função. Partindo dessa hipótese, antes de tentar encontrar a função, o grupo tentou encontrar a medida da reta BC fazendo alguns tratamentos de informação.

Em certo momento, o G6 perguntou a professora se era possível afirmar que a reta BC "é uma função afim", e se assim, admite uma lei de formação. Percebe-se que essa pergunta possibilitou que outros grupos passassem a ver a reta como o gráfico de uma função, e não apenas 
como hipotenusa do triângulo ABC (Figura 3).

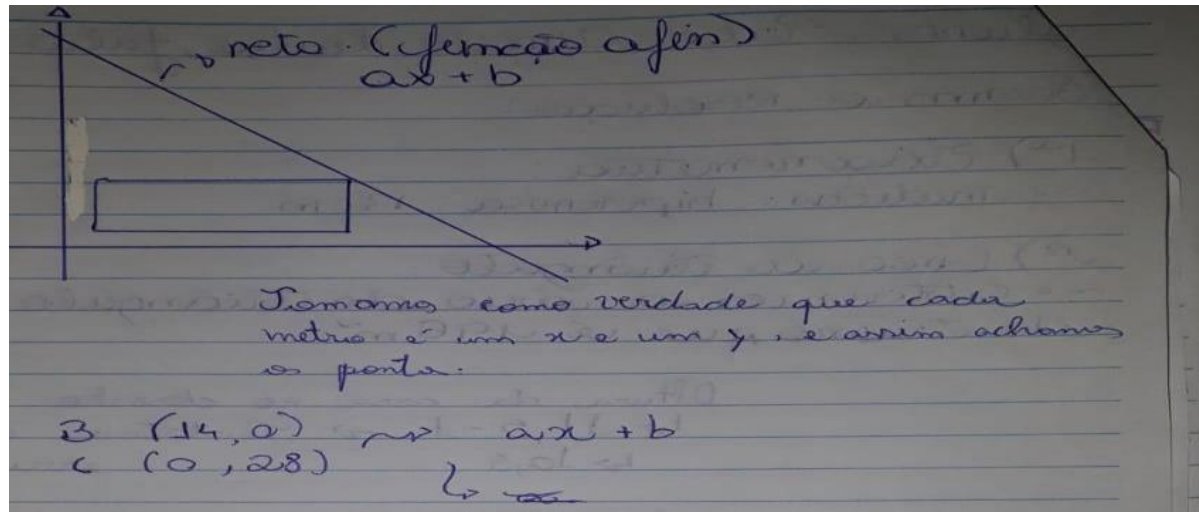

Figura 3: Cálculos de $\mathrm{G} 2$ ao perceber que a reta $\mathrm{BC}$ poderia ser vista como gráfico de uma função afim (Dados da Pesquisa)

Os alunos, naquele momento, conseguiram fazer uma conversão do registro geométrico para o algébrico, reconhecendo que a reta é uma representação geométrica de uma função afim.

O grupo G5, após algumas discussões, chamou a professora para auxiliá-los. O grupo mostrou estar com dificuldades de compreender como utilizar as informações postas pelo problema (linguagem natural) com o conceito de função (representação algébrica). A professora os auxiliou utilizando o aplicativo do GeoGebra; manuseando o ponto P no aplicativo fez com que o grupo percebesse que a altura da casa (comprimento) não era a distância de 0 até $y(P)$ devido às restrições impostas pelo Plano Diretor. Diante disso, a altura era dada pela função afim menos 1 metro. Com isso, o grupo calculou os coeficientes da função afim e utilizou a fórmula da área de um retângulo para obter a função área.

Visto que a intervenção colaborou com a compreensão do problema, a professora realizou essa mesma intervenção com todos os grupos, possibilitando que conseguissem transitar entre as diferentes representações. Vale ressaltar que nesse momento a professora insistiu em fazer com que os próprios alunos, observando o aplicativo enquanto ela manuseava-o, tirassem as conclusões de que era necessário subtrair um metro da função base e da função altura, devido às restrições. Apenas o G3 não conseguiu concluir a função área. Esse grupo mostrou grande dificuldade em transitar da representação da figura de um triângulo para a representação algébrica de função. Após a plenária e formalização, a professora voltou a conversar com o grupo que mostrou maior compreensão.

Após a maioria dos grupos encontrar a função área, eles se depararam com a necessidade de aprender algo novo, que seria como calcular o ponto máximo ou mínimo de uma função 
quadrática. Visto que os grupos estavam livres para utilizar os meios de pesquisa disponíveis da sala, como livro didático, internet e GeoGebra, a maioria optou pela consulta de informações na internet antes mesmo de tentar compreender uma maneira de calcular esse valor sozinhos.

Os grupos G5 e G7 utilizaram as fórmulas das coordenadas do vértice da parábola:

$$
x_{v}=-\frac{b}{2 a} \quad y_{v}=-\frac{\Delta}{4 a}
$$

Nelas, $x_{v}$ e $y_{v}$ são as coordenadas do vértice da função quadrática, $a$ e $b$ são coeficientes da função, e $\Delta$ é o discriminante. Esses dois grupos não deduziram a fórmula, apenas utilizaram pesquisas na internet e o livro didático da disciplina de Matemática do primeiro ano do Ensino Médio.

Pelo registro de G5 (Figura 4) percebe-se que o grupo utilizou a fórmula encontrada sem atribuí-la a algum significado, ou seja, não houve a compreensão conceitual. Perceba que no final, ao calcular o $y_{v}$, que seria o resultado da área máxima procurada, o grupo realiza um novo cálculo de área.

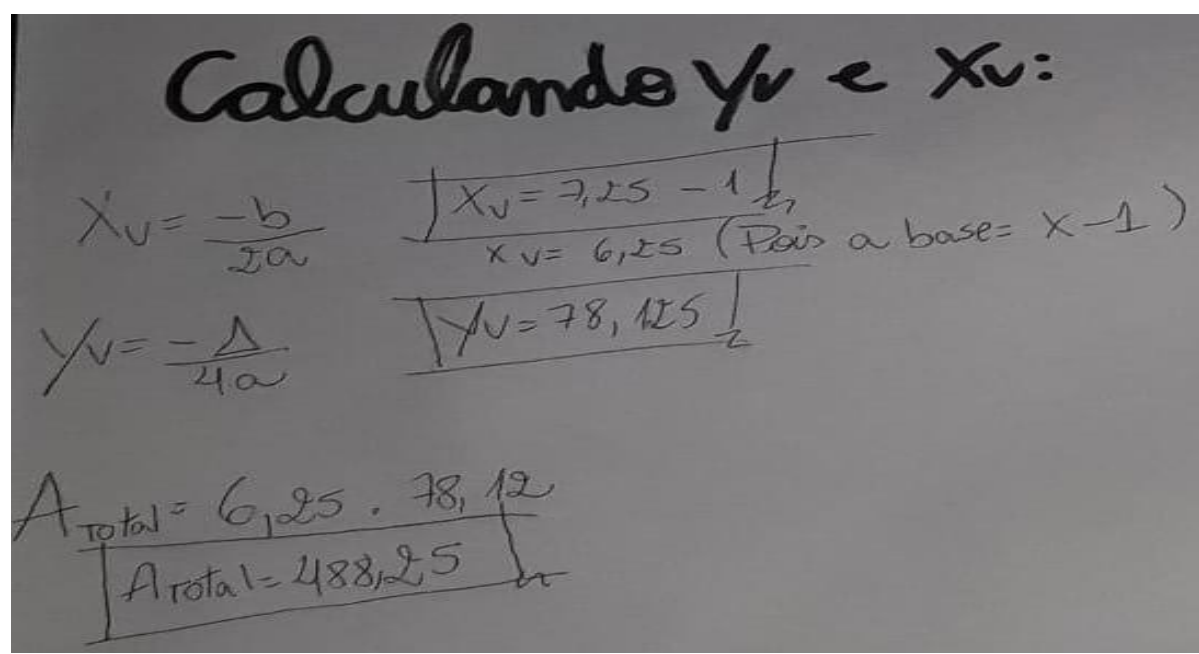

Figura 4: Cálculo da área máxima por G5 (Dados da Pesquisa)

O grupo G7 mostrou não compreender como utilizar a fórmula e cometeu erros algébricos. Porém, sabia que seus cálculos estavam errados, pois o grupo utilizou o aplicativo do GeoGebra para visualizar o gráfico da função e assim conhecer o ponto máximo da função área, como mostra a Figura 5. 


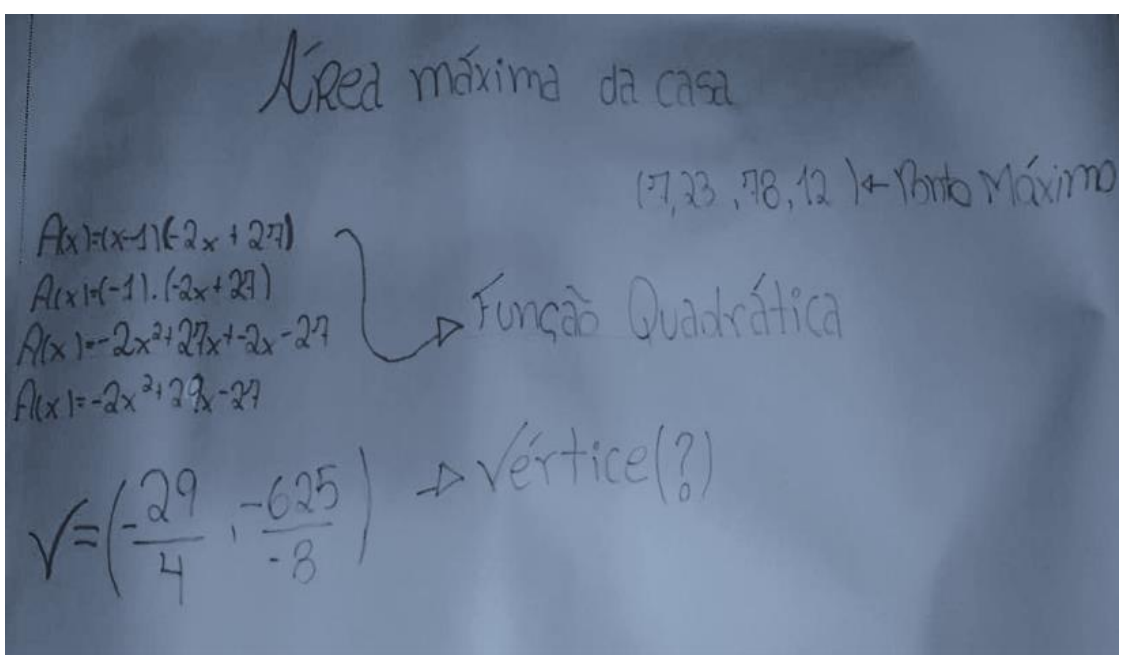

Figura 5: Cálculo da área máxima por G7 (Dados da Pesquisa)

Os grupos G1, G2, G4 e G6 não utilizaram as fórmulas das coordenadas do vértice da parábola já deduzidas; partiram da ideia de que a abscissa do vértice fica no ponto médio do segmento com extremos nas raízes da parábola, ou seja, a média aritmética entre as raízes. Essa ideia pode ter sido obtida como uma conversão do registro gráfico para o algébrico. Para calcular a ordenada no vértice, apenas substituíram na função área o valor encontrado como abscissa do vértice, que são as ideias utilizadas para demonstrar essas fórmulas. A Figura 6, referente aos registros do grupo $\mathrm{G} 4$, ilustra os cálculos realizados.

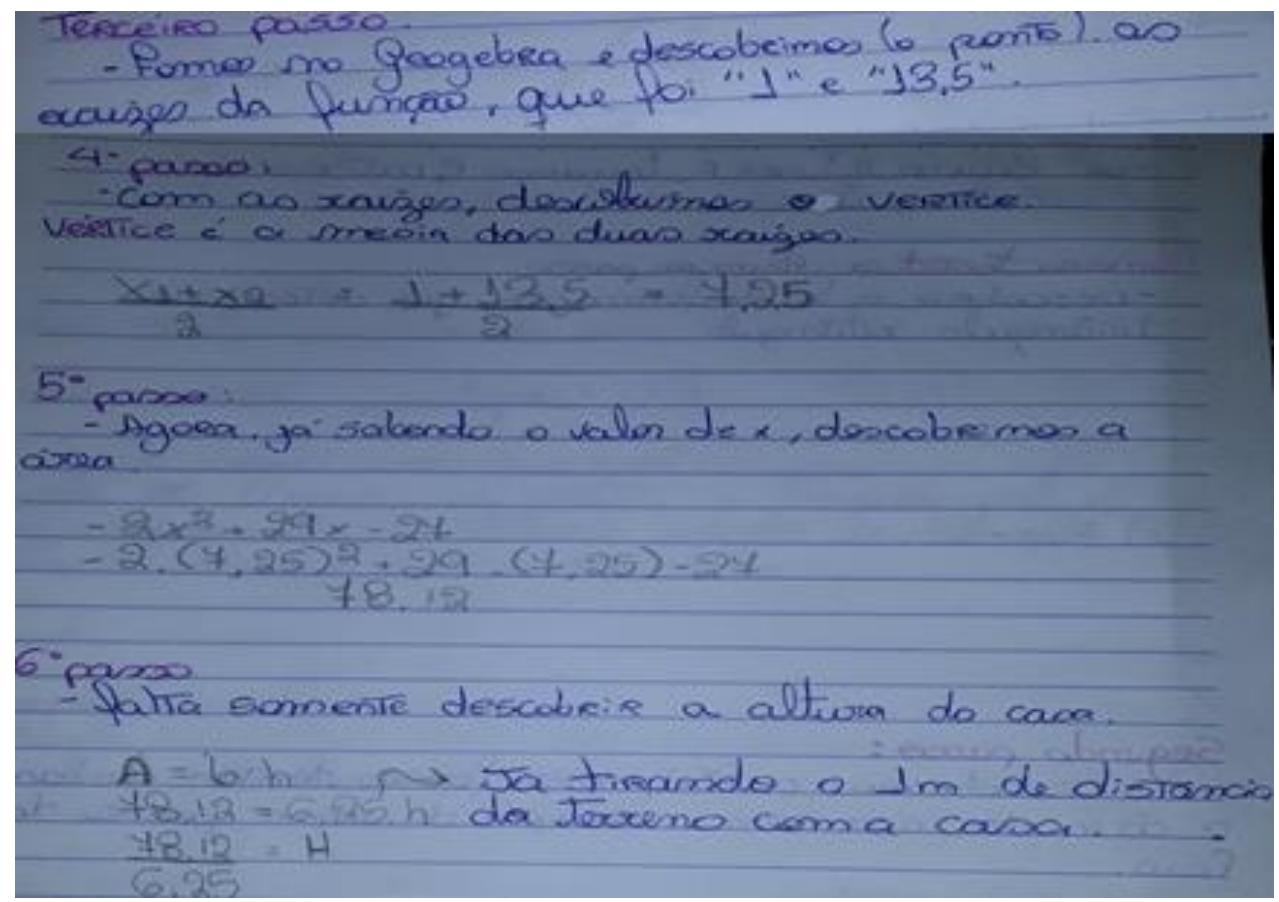

Figura 6: Cálculo da área máxima por G4 (Dados da Pesquisa)

Esses grupos citados, que partiram da hipótese que a abscissa do vértice é média entre 
as raízes, mostraram capacidade em efetivar a conversão entre a representação gráfica e a algébrica.

O grupo G8 conseguiu observar a função área algebricamente, porém, não realizou cálculos para verificar o valor máximo da área da casa, apenas plotou a função no GeoGebra e constatou, pelo gráfico, qual era o valor máximo. O grupo G3 não conseguiu encontrar a função área, nem o respectivo valor da área máxima.

Após todos os grupos terem realizado suas estratégias de resolução, eles as escreveram resumidamente em uma folha $\mathrm{A} 0$, e então, iniciamos a próxima etapa da metodologia, a plenária.

Durante a plenária os grupos afirmaram que o GeoGebra, utilizado com frequência nas aulas de Matemática pela professora, permitiu que houvesse a compreensão sobre o enunciado do problema antes mesmo de manusearem o aplicativo. Porém, ele também foi bastante útil para confrontar as hipóteses.

Um dos grupos afirmou não ter compreendido as fórmulas das coordenadas do vértice da parábola, apenas utilizado. Os demais grupos que mostraram entender, explicaram e apresentaram seus resultados justificando-os pela definição de vértice de parábola como ponto equidistante das raízes. Como quase todos os grupos resolveram utilizando a mesma estratégia por meio de funções, alguns grupos, em plenária, confirmavam ter realizado os mesmos cálculos, mas de ter tentado, além disso, por "tentativa e erro", trigonometria, e até mesmo utilizando a régua. O grupo G5 relata ter percebido seu erro sobre ter multiplicado os resultados em busca da área do terreno enquanto os demais grupos apresentaram.

No segundo dia de experimentação, a professora formalizou o conteúdo utilizando o livro Conexões com a Matemática (LEONARDO, 2013), utilizado pela escola, bem como o livro Matemática: contexto e aplicações (DANTE, 2004). O GeoGebra foi utilizado para apresentar 0 aplicativo "Vértice da parábola e eixo de simetria"4, enquanto a professora definia e demonstrava as fórmulas da abscissa e ordenada do vértice. Além disso, foi utilizado o aplicativo contendo a resposta do problema da casa ${ }^{5}$. Não foi formalizado utilizando o conteúdo de Derivadas, pois nenhum grupo o utilizou como estratégia.

Foi retomada a resolução do problema usando o aplicativo do GeoGebra que apresenta 0 gráfico da função área, conforme Figura 7. Como apenas um grupo não havia resolvido 0

\footnotetext{
4 Link do aplicativo: https://www.geogebra.org/m/yYthTvQg

5 Link do aplicativo: https://ggbm.at/M4tV5J6p
} 
problema, a resolução foi feita rapidamente.
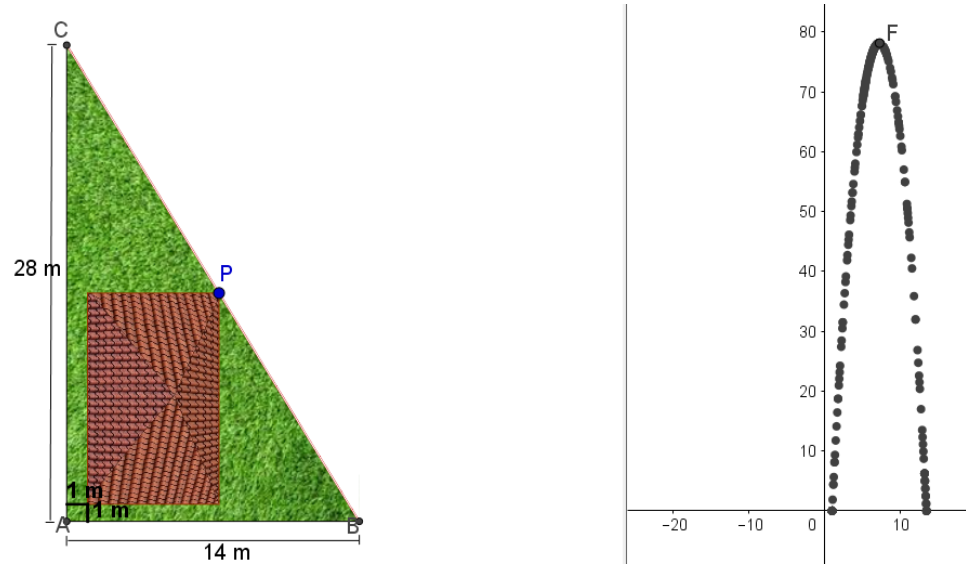

Figura 7: llustração do aplicativo utilizado para colaborar com a resolução do problema usando Funções (CARDOSO, 2018a, p. 68)

Os problemas propostos à turma após a experimentação já não fizeram parte desse trabalho, visto que até naquele momento usávamos como referência as etapas da metodologia de ensino-aprendizagem-avaliação através da resolução de problemas apresentadas no artigo de Allevato e Onuchic (2008), o qual não comportava a etapa dez.

Os alunos foram avaliados constantemente durante o desenvolvimento da atividade, tanto pela participação e discussão das atividades propostas, bem como, pelos registros entregues à professora. Os grupos levaram, em média, 1h15min para solucionar o problema.

\subsection{Experiência na turma do Ensino Superior}

A situação-problema experimentada também se refere ao cálculo da área máxima de uma casa, conforme apresenta o Quadro 2. A atividade apresenta algumas alterações em relação ao enunciado e ao nome dos vértices do triângulo, que antes era $A B C$ (Quadro 1), e agora OMN. A alteração no enunciado se deu para melhorar a coerência dele e a dos vértices para que os alunos não confundissem os vértices $A, B$ ou $C$ com os coeficientes $a, b$ e $c$ da função quadrática enquanto discutiam em grupos.

Quadro 2: Atividade aplicada a turma do Ensino Superior — Problema 1 Área da Casa

\section{Problema 1 - Área máxima da casa}

José ganhou como herança um terreno triangular, conforme a Figura 1, e deseja construir uma casa retangular com a maior área possível. Entretanto, ele precisa respeitar algumas restrições impostas pelo Plano Diretor de sua cidade para a construção. Algumas das restrições são que o canto indicado pelo ponto $\mathrm{P}$ fique sobre a lateral $\mathrm{MN}$ do terreno e seja 
um dos cantos da casa, e que as laterais da casa, paralelas aos lados OM e ON do terreno, devem ficar a $1 \mathrm{~m}$ de distância desses lados.

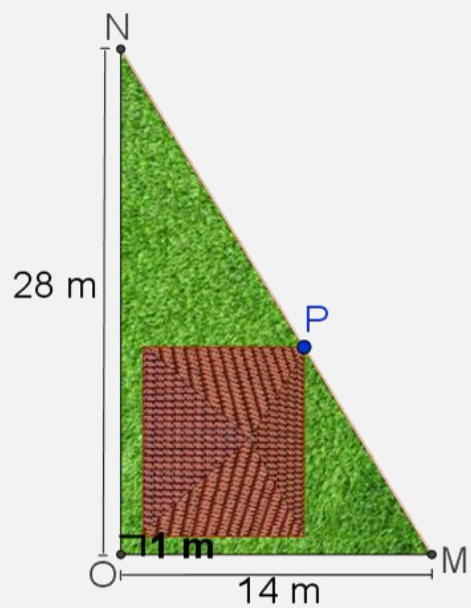

Figura 1: Construção de uma casa em um terreno triangular (adaptada de Cardoso, 2016, p. 92) Ajude José encontrar as medidas da casa, que deverá construir, para que a área dela seja máxima.

$$
\text { Fonte: Cardoso (2018a, p. 88) }
$$

Assim que foi distribuída a situação-problema, a professora disponibilizou 0 aplicativo ${ }^{6}$ referente a atividade.

De maneira geral, analisando os dados obtidos na resolução do problema (quarta etapa), quase todos os grupos calcularam em algum momento o valor da semirreta MN (hipotenusa do triângulo) utilizando o Teorema de Pitágoras. Percebemos que os grupos tentam essa estratégia por conta de o formato do triângulo remeter à Geometria Plana, e esse ser um valor desconhecido do problema.

A maioria dos grupos percebeu a relação existente entre a variação da área e o conteúdo de funções, bastante presente na disciplina de CDI I. Porém, nem todos conseguiram utilizar esses conceitos algebricamente.

Alguns grupos utilizaram semelhança de triângulos como uma estratégia de resolução, porém, mesmo que em algumas situações o conceito matemático estava correto, os valores utilizados não estavam. Isso deve-se às restrições impostas pelo problema. A maioria desses grupos acreditava que a distância máxima entre o ponto 0 e $0 \times(P)$ seria 13, e entre o ponto 0 e o $y(P)$ seria 27, pois para eles bastava subtrair 1 metro das laterais. Nesse momento os grupos já estavam com o aplicativo do GeoGebra em mãos.

Dois grupos conseguiram encontrar uma função área que possivelmente representava a

\footnotetext{
${ }^{6}$ Link do aplicativo da situação-problema: https://www.geogebra.org/m/A5beu8fr
} 
variação da área da casa; calcularam a derivada da função e o zero da função derivada para obter a abscissa do ponto máximo da área. Quatro grupos se basearam na ideia de que a área máxima é obtida pelo ponto médio do triângulo (terreno). E um dos grupos, partiu da ideia de semelhança de triângulos.

Partindo para uma abordagem específica dos grupos, iniciamos analisando E4, que representou as restrições corretamente. Após constatar no GeoGebra o valor máximo de 0 até $x(P)$ e de $O$ até $y(P)$, E4 utilizou semelhança de triângulos para provar os reais valores possíveis na altura e base do triângulo sem as restrições. Feito isso, o grupo verificou a partir de cálculos que o ponto médio é onde obtemos a área máxima (Figura 8), todavia, os cálculos para demonstrar que essa hipótese não foram registrados na folha entregue à professora.

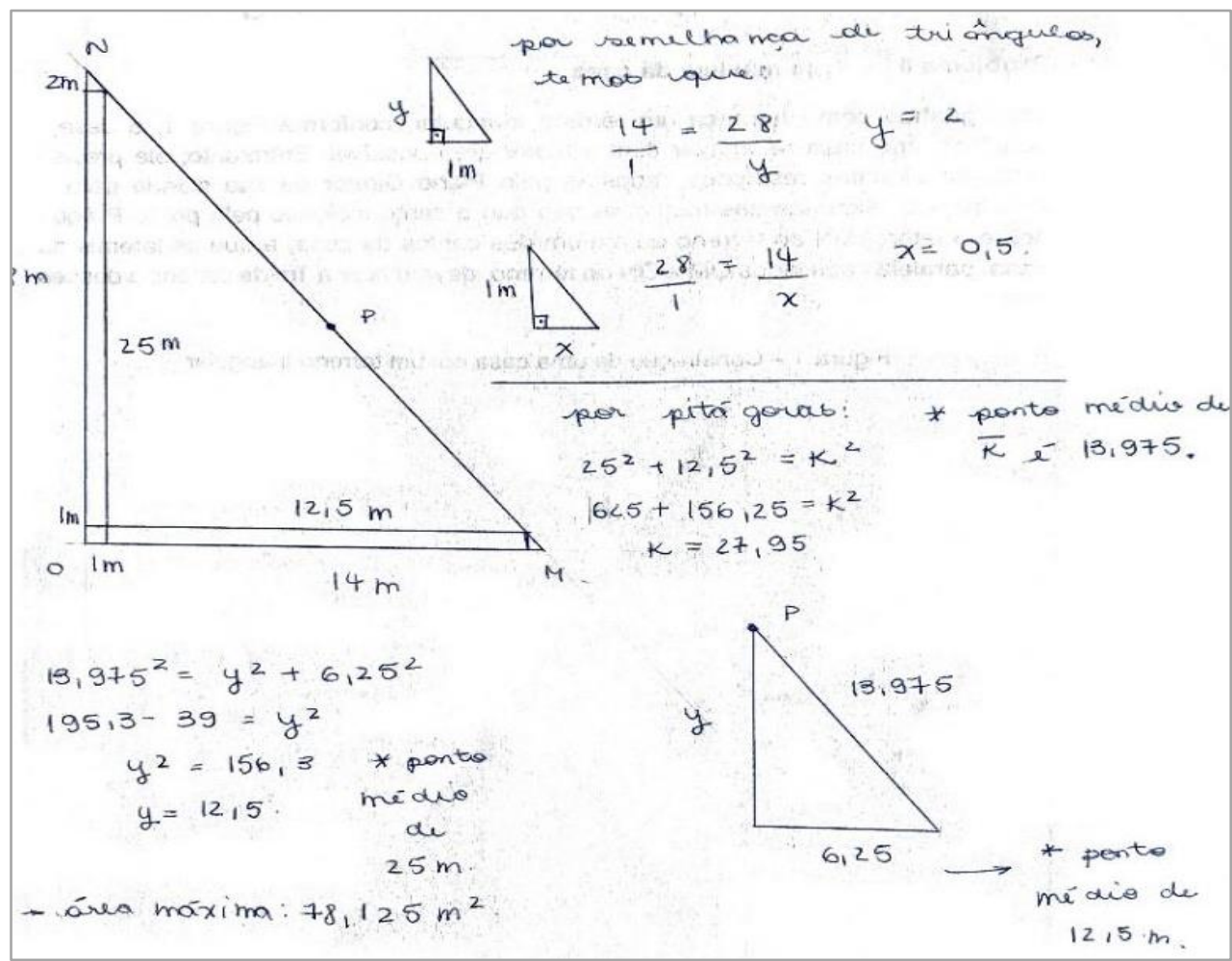

Figura 8: Estratégia E4 (Dados da Pesquisa)

Enquanto alguns membros do grupo E4 discutiam e resolviam o problema usando ponto médio, um outro membro encontrava a função área que é obtida pela relação de base (largura) e altura (comprimento) da casa. Esse membro do grupo utilizou sistemas lineares para tentar encontrar os coeficientes $a, b$ e $c$ de uma função quadrática (função área da casa), e conceito de tangente, porém, por relatos do aluno, ele disse não ter conseguido concluir devido ao tempo, mas pelas anotações dele entregue a professora (Figura 9) seus conceitos estavam corretos. 


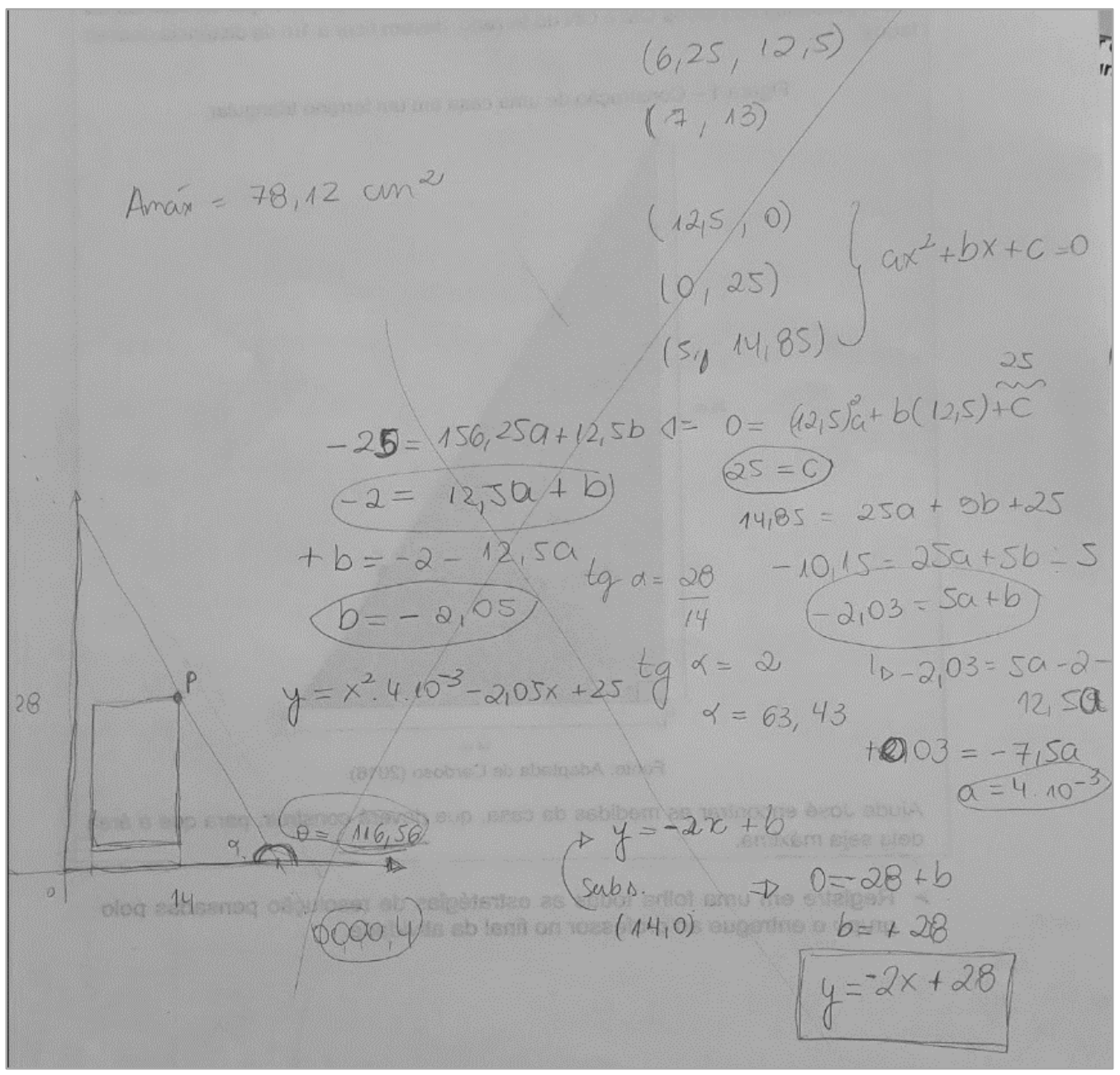

Figura 9: Estratégia de um dos alunos do grupo E4 (Dados da Pesquisa)

Esse aluno fez uma conversão do registro geométrico para o algébrico, mostrando ter compreendido o problema em questão.

Partindo para o E6, que é formado por um único aluno, temos apenas um registro entregue por ele. Percebe-se que o problema foi resolvido utilizando semelhança de triângulos, funções e derivada. $O$ único erro foi ter utilizado as medidas $27 \mathrm{~m}$ e $13 \mathrm{~m}$ para o terreno, ao invés de $25 \mathrm{~m}$ e 12,5m. O aluno optou por não apresentar e nem passar a resolução para a folha A0. Pela Figura 10 podemos verificar seus cálculos. 


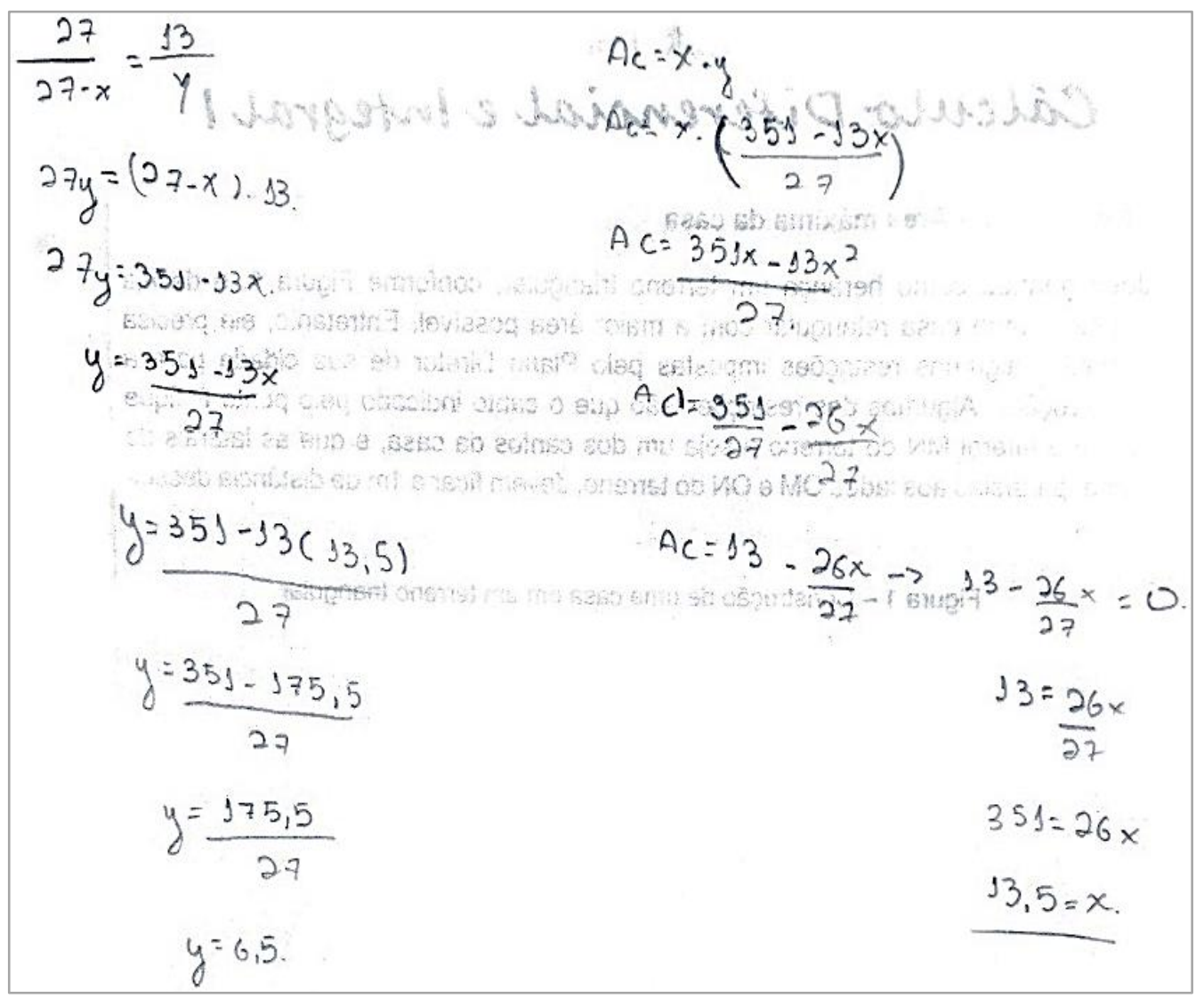

Figura 10: Estratégia E6 (Dados da Pesquisa)

Mesmo que esteja parcialmente correta essa resolução, E6 não considerou o domínio das funções e nem verificou se o ponto crítico é máximo ou mínimo.

Pelos registros do grupo E3 e observação, percebe-se que uma de suas estratégias foi utilizando funções, e inclusive encontraram uma função a qual o grupo achava que deveria ser a função área. Todavia, além de usarem as restrições algebricamente erradas, a função que encontraram é similar à função altura (comprimento) da casa, e não à sua área. $O$ grupo percebeu que essa não era a função área, pois não era possível encontrar seu valor máximo (Figura 11).

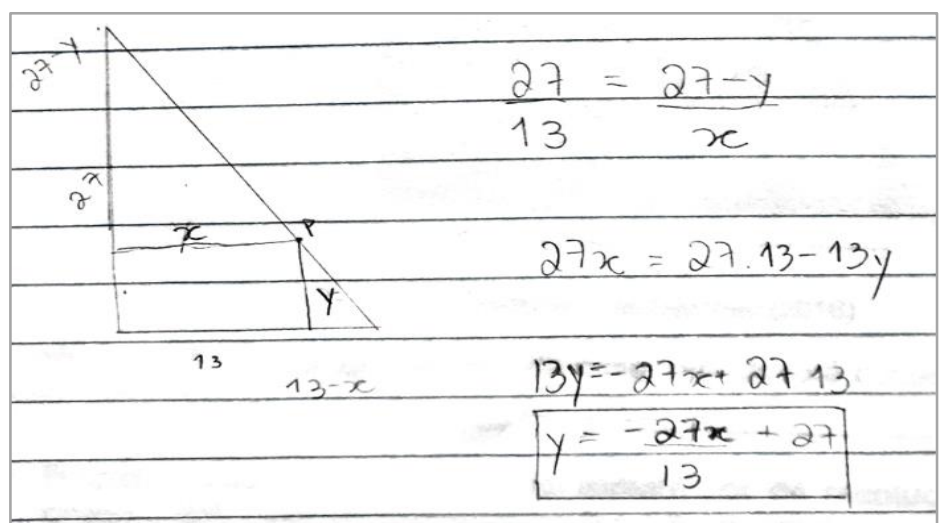

Figura 11: Estratégia do grupo E3 (Dados da Pesquisa) 
Outra estratégia desse grupo foi usando semelhança de triângulos, inclusive, percebe-se que o grupo optou pela semelhança de triângulos por ser um conteúdo previamente visto em sala, mas de todo modo, ainda não conseguiram resolver o problema.

O grupo E7 utilizou uma estratégia baseada em conceitos de Trigonometria e Funções, realizando a conversão desses registros em diversos momentos. Pelo registro entregue pelo grupo subentende-se que E7 divide o triângulo OMN em três partes: OXN, OYM, BMN. A Figura 12 ilustra o que o grupo objetivava fazer.

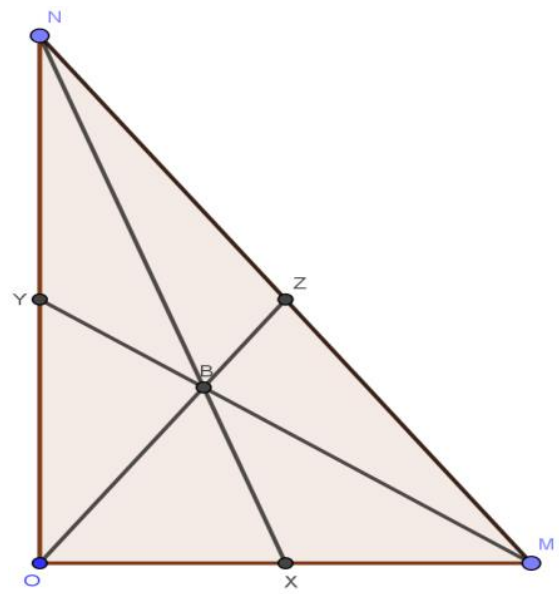

Figura 12: llustração da estratégia de E7 (CARDOSO, 2018a, p. 97)

Feito isso, E7 igualou a área do triângulo OMN, a soma das áreas dos triângulos OXN e OYM, em função de $X$ e $Y 7$. Ao isolar a variável $Y$, obteve a função altura da casa (desconsiderando que há o erro em relação as restrições impostas pelo problema). Sendo assim, tem-se que sendo $\mathrm{X}$ a base e $\mathrm{Y}$ a altura da casa, a área é obtida a partir do produto dessas variáveis. A partir disso, E7 encontrou a função derivada e calculou o zero da função derivada para obter o valor de máximo do retângulo OXPY (ou OXZY). Essa estratégia estaria correta se não fosse o erro em relação às restrições, porém, pelo registro do E7 (Figura 13) percebe-se que o grupo pode não ter utilizado os conceitos necessários da Geometria Plana que garantem que as informações são verdadeiras. Ou seja, o grupo não poderia ter adicionado as áreas dos triângulos OXN e OYM e igualado a área total de OMN, sem considerar que $\mathrm{X}$ e $\mathrm{Y}$ são os pontos médios dos catetos desse triângulo. Já que, por definição de mediana e triângulos equivalentes, sendo o ponto $B$ (Figura 12) o baricentro do triângulo OMN, a área do quadrilátero OXBY é congruente ao do triângulo BMN, assim garantindo que a soma OXN e OYM corresponde a área total de OMN.

\footnotetext{
7 Utilizaremos a notação $X$ e $Y$ para nos referirmos a vértices do triângulo e ao mesmo tempo variáveis, já que para que essa estratégia esteja correta, $\mathrm{X}$ e $\mathrm{Y}$ precisam ser ponto médio do triângulo.
} 
Ainda descrevendo sobre $E 7$, esse grupo optou por não representar sua estratégia na folha $\mathrm{A} 0$ e nem apresentar em plenária. Mesmo que sua estratégia inicial era um tanto quanto diferente das demais, percebe-se que ao encontrar uma função quadrática 0 grupo utilizou 0 conceito de derivada para obter o ponto de máximo, assim como E6. Todavia, não foi apresentado o domínio das funções, e nem averiguado se o ponto crítico era um ponto de máximo ou mínimo. Com isso, verifica-se que houve pouco comprometimento do grupo em relação a formalização matemática.

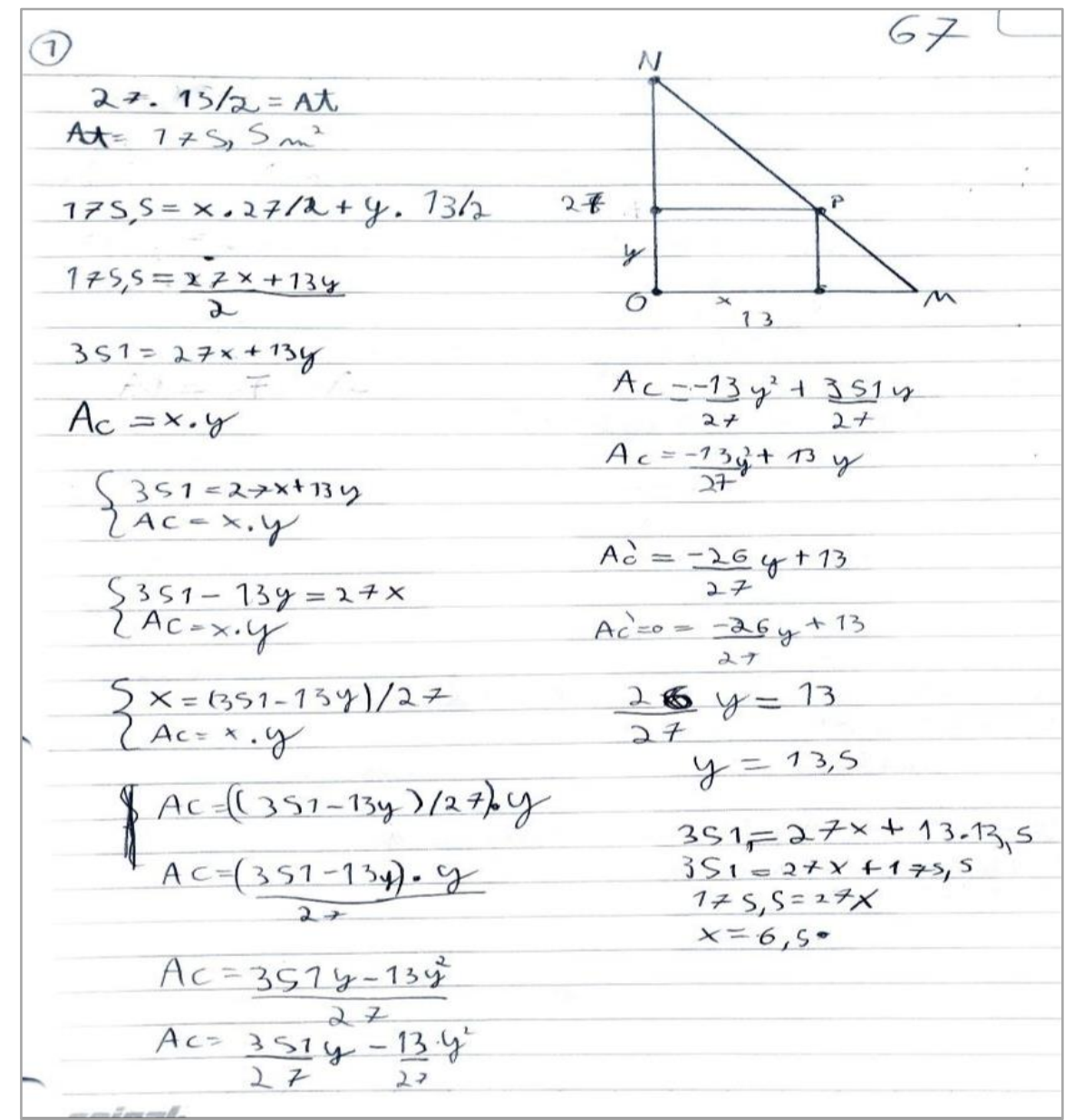

Figura 13: Estratégia E7 (Dados da Pesquisa)

O Grupo E2 partiu da ideia intuitiva de que a área máxima da casa é obtida pelo ponto médio do triângulo descontando as restrições. Cometeu o mesmo erro que alguns dos demais grupo em relação ao uso das restrições. Eles utilizaram o GeoGebra para verificar se a área máxima da casa, sendo aproximadamente $78 \mathrm{~m}^{2}$, tendo como base a metade de $13 \mathrm{~m}$, e altura a metade de $27 \mathrm{~m}$. Assim que perceberam que não era exatamente a metade, considerando um triângulo de $13 \mathrm{~m}$ por $27 \mathrm{~m}$, partiram para a leitura de um outro problema, também aplicado, que não será abordado nesse artigo, mas pode ser consultado em Cardoso (2018a). 
O grupo E5 percebeu por meio do GeoGebra as medidas impostas pelo plano diretor, todavia, não apresentou uma resolução coerente para o problema.

Em relação a plenária, parte dela ocorreu no primeiro dia de experimentação, e o restante no segundo dia. O grupo E3 optou por iniciar a apresentação das estratégias, comentando como utilizaram algebricamente as restrições impostas pelo problema. Como já relatado nos resultados, esse grupo, assim como outros, apenas subtraiu um metro das laterais obtendo um novo triângulo com medidas $13 \mathrm{~m}$ de base e $27 \mathrm{~m}$ de altura. A professora deixou 0 grupo concluir sua apresentação e perguntou aos demais grupos se mais alguém fez processo similar. Apenas um grupo responde que não. Alguns não se manifestaram. A professora, utilizando o GeoGebra, moveu o ponto $P$ até seu mínimo em MN e depois até seu máximo, possibilitando que a turma percebesse que não bastava subtrair um metro. A professora questionou a turma por que não é suficiente apenas fazer isso. Um membro do grupo E4 respondeu ser "porque tem que fazer Pitágoras naqueles triangulozinhos ali". Um dos membros do E2 falou para seu próprio grupo "Por isso que não estava dando certo". A professora deu continuidade a essa breve explicação, sem realizar cálculos, visto que isso seria feito na formalização. O E4, quando iniciou a apresentação, disse que alguns membros do grupo pensaram diferente um do outro, como já relatado nos resultados. Alguns grupos optaram por não apresentar, e os demais grupos que apresentaram, foram estratégias semelhantes.

Concluída a plenária, foi realizada a formalização do conteúdo, paralelamente à resolução dos problemas. Mesmo a professora questionando em vários momentos a turma sobre o que fazer, como fazer e se foi compreendido, não houve muita participação dos alunos durante a formalização do conteúdo, um comportamento diferente do que ocorreu na plenária.

A professora formalizou o conteúdo utilizando os conceitos algébricos de função, e recorrendo ao aplicativo ${ }^{8}$ do GeoGebra quando necessário, com o objetivo de facilitar a partir da visualização o que era dito. Para formalizar o teste da primeira derivada a professora utilizou 0 PowerPoint, disponibilizado pela professora regente, que apresentava sua definição, além de utilizar o aplicativo do GeoGebra que apresenta a função área (Figura 14), para que o aluno relacionasse o gráfico com a parte algébrica representada no quadro branco.

\footnotetext{
${ }^{8}$ Link do aplicativo: https://www.geogebra.org/m/QpB7Z5wg
} 


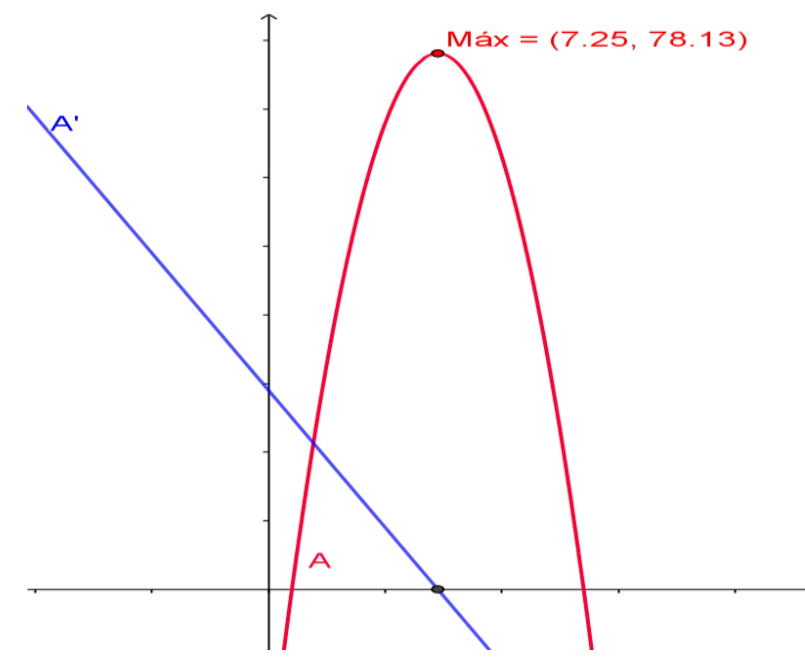

Figura 14: llustração da análise do teste da primeira derivada na função área da casa do Problema 1 (sem restringir o domínio) (CARDOSO, 2018a, p. 107)

Com isso, foi calculado a área máxima e as medidas da casa. Para formalizar o Teste da Segunda Derivada, a professora utilizou outro problema que também foi aplicado e pode ser conferido na íntegra em Cardoso (2018a).

Feita a formalização, a professora entregou aos alunos uma lista contendo outros problemas de Otimização, leu alguns dos problemas com a turma e enfatizou que o uso do GeoGebra poderia ser fundamental na resolução de alguns deles, porém deixou a lista como tarefa.

Não foi realizada a formalização do problema 1 utilizando a estratégia de ponto médio feita por alguns grupos devido ao limite de aulas concedidas pela professora regente para realização da atividade. A avaliação foi realizada durante a experimentação, enquanto eram analisadas as discussões dos grupos e a discussão em plenária.

\section{Conclusões}

A possibilidade de aliar a metodologia de resolução de problemas e a tecnologia pode favorecer o ensino e a aprendizagem de máximos e mínimos de funções, nos diferentes níveis de ensino. A tecnologia na resolução de problemas foi trabalhada como um meio de o professor proporcionar ao aluno um ambiente de manipulação dinâmica algébrica/gráfica da situaçãoproblema, instigando-o a criação de conjecturas, investigação de hipóteses, visualização de comportamento de funções, visando ao desenvolvimento de um conhecimento intuitivo de otimização de funções que é necessário para a compreensão e aprendizagem desse conteúdo. 
Nas experimentações realizadas, observamos que ao abordarmos a situação-problema da área máxima da casa por meio da metodologia de ensino-aprendizagem-avaliação através da resolução de problemas com a tecnologia, essa permitiu aos alunos possibilidades de criar hipóteses e estratégias de resolução do problema

Em ambas as experimentações os alunos necessitaram utilizar seus conhecimentos prévios para dar continuidade à resolução do problema. Isso vai ao encontro do que afirma Allevato e Onuchic (2014), em relação ao aluno buscar conhecimentos prévios para ampliar suas estratégias de resolução.

Na turma do Ensino Médio, em que as resoluções foram realizadas utilizando o conceito de função principalmente, constata-se que a ordem das conversões aumenta a dificuldade do aluno (DUVAL, 2009). Os alunos tiveram dificuldade em converter as representações da função afim do registro gráfico para o algébrico, e após superar essa dificuldade a resolução do problema fluiu com mais facilidade.

Embora alguns alunos tenham buscado resolver o problema utilizando a fórmula do vértice ou ponto médio, devemos enfatizar a importância em explorar o conceito de máximos e mínimos pela compreensão do problema, incentivando os alunos a investigar e refletir sobre o uso de fórmulas. Nesse contexto, a tecnologia pode ter um papel essencial. Em relação ao GeoGebra, ele foi fundamental para que o grupo pudesse visualizar, conjecturar, criar intuições sobre a resolução do problema e articular entre as diferentes representações do problema (ALLEVATO, JAHN e ONUCHIC, 2017). Além disso, os alunos utilizaram o GeoGebra para confirmar o resultado da resolução do problema e realizar os cálculos de derivada ou raízes da função (SILVA, 2010). Após encontrar a função área, quase todos os grupos escreveram a função na caixa de entrada do software, e visualizaram a representação gráfica da função. Todavia, embora os alunos tenham preferência por métodos visuais, dificilmente buscam resolver o problema pela representação gráfica.

A formalização, além de servir para organizar e estruturar em linguagem matemática os conceitos sobre Otimização de Funções, foi um momento para discutir com os alunos as dúvidas e erros que cometeram durante a resolução do problema, além disso, no Ensino Superior serviu para evidenciar a conexão da derivada com o estudo de funções do Ensino Médio. $O$ auxílio do GeoGebra, durante a formalização, possibilitou que os conceitos sobre os testes da primeira derivada fossem visualizados, e no caso do Ensino Médio, transitaram da representação algébrica 
do $x$ do vértice para a representação gráfica, como a média entre as raízes. $O$ uso de mais de uma representação semiótica, favorece a aprendizagem do aluno, já que segundo Duval (2012a), o indivíduo só aprende quando transita por pelo menos dois registros de representação do objeto.

Em relação a atuação do professor, foi possível vivenciar alguns desafios durante cada experimentação. Na turma do Ensino Médio, a professora regente teve imprevisto com a tecnologia, mas que pôde ser resolvido parcialmente, já que alguns dos alunos portavam seus próprios notebooks. Na turma da Graduação, diferente do Ensino Médio, a metodologia utilizada já era de conhecimento deles, visto que a professora regente a utilizou em algumas de suas aulas. Contudo, inicialmente percebeu-se que nem todos os alunos estavam satisfeitos com a ideia de formarem grupos, tanto que um aluno optou por realizar a atividade individualmente. Além disso, enquanto a professora e autora observava e incentivava, foi percebido um pouco de timidez e recusa vinda da maioria dos grupos, dificultando a abordagem da professora. Outra dificuldade percebida foi a rejeição da maioria dos grupos dessa turma quando a professora solicitou que participassem da plenária, inclusive, houve grupos que optaram por não participar, o que pode inibir dados de pesquisa relacionados a aprendizagem dos alunos. Já na turma do Ensino Médio, não houve dificuldades na formação dos grupos ou na participação da plenária. Esses desafios, presentes na prática do professor, devem ser tomados como momentos de reflexões sobre a nossa prática pedagógica e como podemos, conjuntamente, promover um ambiente de maior interação em sala de aula.

Ademais, espera-se que o Caderno Didático (CARDOSO, 2018b), o qual apresenta a atividade experimentada, e diversas outras que podem ser utilizadas por professores e alunos no contexto de máximos e mínimos com auxílio do GeoGebra, sejam exploradas e que possam contribuir com o ensino e aprendizagem nessa área da Matemática tão importante.

\section{Agradecimentos}

Agradecemos à Fundação de Amparo à Pesquisa e Inovação do Estado de Santa Catarina (FAPESC) pelo apoio financeiro e ao Grupo de Pesquisa em Educação Matemática e Sistemas Aplicados ao Ensino (PEMSA). 


\section{Referências}

ALLEVATO, Norma Suely Gomes. Associando o computador à resolução de problemas fechados: análise de uma experiência. 2005. 378f. Tese (Doutorado em Educação Matemática) — Instituto de Geociências e Ciências Exatas. Universidade Estadual Paulista. Rio Claro.

ALLEVATO, Norma Suely Gomes; JAHN, Ana Paula; ONUCHIC, Lourdes de La Rosa. O computador no ensino e aprendizagem de Matemática: reflexões sob a perspectiva da resolução de problemas. In: ONUCHIC, Lourdes de la Rosa; LEAL JR., Luiz Carlos; PIRONEL, Márcio. Perspectivas para resolução de problemas. São Paulo: Livraria da Física, 2017, p. 247-277.

ALLEVATO, Norma Suely Gomes; ONUCHIC, Lourdes de la Rosa. Teaching Mathematics in the classroom through problem solving. In: 11th INTERNATIONAL CONGRESS ON MATHEMATICAL EDUCATION, 11, 2008, Monterrey. Proceedings of the ICME11. ICME: Monterrey, 2008, p. 59-70.

ALLEVATO, Norma Suely. Gomes; ONUCHIC, Lourdes de la Rosa. Ensino-aprendizagemavaliação de Matemática: por que através da resolução de problemas? In: ONUCHIC, Lourdes de la Rosa; ALLEVATO, Norma Suely Gomes; NOGUTI, Fabiane Cristina Hopner; JUSTILIN, Andressa Maria. (Org.). Resolução de Problemas: teoria e prática. Jundiaí: Paco Editorial, 2014, p. 35-52.

ALMEIDA, Conceição; VISEU, Floriano. Interpretação gráfica das derivadas de uma função por professores estagiários de Matemática. Revista Portuguesa de Educação, Braga, v. 15, n. 1, p. 193-219, jan./jun. 2002.

BOGDAN, Robert; BIKLEN, Sari Knopp. Investigação Qualitativa em Educação: uma introdução à teoria e aos métodos. Tradução de Maria João Avarez, Sara Bahia dos Santos e Telmo Mourinho Baptista. Porto: Porto Editora, 1994.

BORBA, Marcelo de Carvalho; PENTEADO, Maria Godoy. Informática e Educação Matemática. 3. ed. Belo Horizonte: Autêntica, 2007.

BRASIL. Ministério da Educação. Secretaria de Educação Básica. PCN+ Ensino Médio Orientações Educacionais Complementares aos Parâmetros Curriculares Nacionais: Ciências da Natureza, Matemática e suas Tecnologias. Brasília: MEC/SEB, 2002.

CARDOSO, Dienifer Tainara. Máximos e Mínimos: situações-problema com recursos dinâmicos. 2018b. 91f. Produto Educacional (Mestrado em Ensino de Ciências, Matemática e Tecnologias) Centro de Ciências Tecnológicas. Universidade do Estado de Santa Catarina. Joinville.

CARDOSO, Dienifer Tainara. Resolução de problemas e o software GeoGebra no ensino e aprendizagem de otimização de funções. 2018a. 156f. Dissertação (Mestrado em Ensino de Ciências, Matemática e Tecnologias) - Centro de Ciências Tecnológicas. Universidade do Estado de Santa Catarina. Joinville.

CARDOSO, Dienifer Tainara. Teorema Fundamental do Cálculo: uma abordagem dinâmica. 2016. 132f. Monografia (Licenciatura em Matemática) — Centro de Ciências Tecnológicas. Universidade do Estado de Santa Catarina. Joinville.

DANTE, Luiz Roberto. Matemática: contexto e aplicações. v. 1. 3 ed. São Paulo: Ática, 2004. 
DUVAL, Raymond. Diferenças semânticas e coerência matemática: introdução aos problemas de congruência. Tradução de Méricles Thadeu Moretti. Revemat, Florianópolis, v. 7, n. 1, p. 97-117, jan./jun. 2012b.

DUVAL, Raymond. Registros de representação semiótica e funcionamento cognitivo do pensamento. Tradução de Méricles Thadeu Moretti. Revemat, Florianópolis, v. 7, n. 2, p. 266-297, jul./dez. 2012a.

DUVAL, Raymond. Registros de representações semióticas e funcionamento cognitivo da compreensão em Matemática. In: MACHADO, Silva Dias Alcântara. (Org.) Aprendizagem em Matemática: registros de representação semiótica. 8. ed. Campinas: Papirus, 2013, p. 14-27.

DUVAL, Raymond. Semiósis e pensamento humano: registro semiótico e aprendizagens intelectuais. Tradução de Lênio Fernandes Levy e Marisa Rosâni Abreu da Silveira. São Paulo: Livraria da Física, 2009.

LEMKE, Raiane; SIPLE, Ivanete Zuchi. Funções reais de duas variáveis e GeoGebraBook: recursos dinâmicos para o ensino de Cálculo. BOEM, Joinville, v. 6, n. 11, p. 18-36, out. 2018.

LEONARDO, Fabio Martins de. (Ed.). Conexões com a Matemática. v. 2, 3. ed., São Paulo: Moderna, 2013.

MARIN, Douglas; PENTEADO, Miriam Godoy. Professores que utilizam tecnologia de informação e comunicação para ensinar Cálculo. Educação Matemática Pesquisa, São Paulo, v. 13, n. 3, p. 527-546, set./dez. 2011.

ONUCHIC, Lourdes de la Rosa; ALLEVATO Norma Suely Gomes. Novas reflexões sobre o ensinoaprendizagem de Matemática através da resolução de problemas. Educação Matemática: pesquisa em movimento. 4. ed. São Paulo: Cortez, 2012.

ONUCHIC, Lourdes de la Rosa; ALLEVATO, Norma Suely Gomes. Pesquisa em Resolução de Problemas: caminhos, avanços e novas perspectivas. Bolema, Rio Claro, v. 25, n. 4, p. 73-98, dez. 2011.

RICHIT, Andriceli. Aspectos conceituais e instrumentais do conhecimento da prática do professor de Cálculo Diferencial e Integral no contexto das tecnologias digitais. 2010. 243f. Dissertação (Mestrado em Educação Matemática) — Instituto de Geociências e Ciências Exatas. Universidade Estadual Paulista. Rio Claro.

RICHIT, Andriceli; BENITES, Vanessa Cerignoni; ESCHER, Marco Antonio; MISKULIN, Rosana Giaretta Sguerra. Contribuições do software GeoGebra no estudo de Cálculo Diferencial e Integral: uma experiência com alunos do curso de Geologia. Revista do Instituto GeoGebra Internacional de São Paulo, São Paulo, v. 1, n. 1, p. 90-99, jan./jun. 2012.

SBEM - Sociedade Brasileira de Educação Matemática. A formação do professor de Matemática nos cursos de licenciatura: reflexões produzidas pela comissão paritária. Boletim Informativo, $\mathrm{n}$. 21. 
SILVA, Fernanda Laureano. Matemática \& Educação: uma proposta pedagógica no ensino do Cálculo. 2010. 57p. Monografia (Especialização em Matemática) — Instituto de Ciências Exatas. Universidade de Federal de Minas Gerais. Belo Horizonte.

VAZ, Francieli Aparecida; GOMES, Ana Paula Falcão. Resolução de problemas matemáticos: desafios da Graduação. In: ENCONTRO REGIONAL DE ESTUDANTES DE MATEMÁTICA DA REGIÃO SUL, XX, 2014, Bagé. Anais do XX EREMAT. Bagé: UNIPAMPA, 2014, p. 556-563.

VERHOEF, Nellie C.; COENDERS, Fer; PIETERS, Jules M.; SMAALEN, Daan van; TALL, David Orme. Professional development through lesson study: teaching the Derivative using GeoGebra. Professional Development in Education, v. 41, n. 1, p. 109-126, 2015.

VISEU, Floriano. Representações na aprendizagem da derivada de uma função por alunos do ensino secundário. Zetetiké, Campinas, v. 25, n. 2, p. 265-288, maio/ago. 2017. 